\title{
BAP1 Germline Mutation Associated with Bilateral Primary Uveal Melanoma
}

\author{
Michael D. Yu Babak Masoomian Jerry A. Shields Carol L. Shields \\ Ocular Oncology Service, Wills Eye Hospital, Thomas Jefferson University, Philadelphia, PA, USA
}

\section{Established Facts}

- Mutation in BRCA-associated protein 1 (BAP1) is strongly associated with hereditary uveal melanoma and other systemic malignancies.

- However, no genes to date have been implicated in the pathogenesis of bilateral uveal melanoma.

\section{Novel Insights}

- Two cases of patients with bilateral uveal melanoma and germline BAP1 mutation suggest BAP1 could contribute to the pathogenesis of bilateral uveal melanoma.

\section{Keywords}

Uvea - Bilateral melanoma $\cdot$ BAP1 $\cdot$ BRCA-associated protein 1

\begin{abstract}
Purpose: To describe the occurrence of bilateral primary uveal melanoma in 2 patients with mutation on the gene encoding BRCA1-associated protein 1 (BAP1). Methods: Retrospective chart review of patients with bilateral primary uveal melanoma and subsequent positive germline BAP1 mutation. Results: There were 2 patients with bilateral uveal melanoma and BAP1 germline positivity. Neither patient demonstrated oculodermal melanocytosis. Patient 1 underwent enucleation of his right eye (OD) at the age of 44 years for a 9.6-mm-thick choroidal melanoma. He returned 4 years later with a 10.0-mm-thick choroidal melanoma in his left
\end{abstract}

\section{KARGER}

(c) 2019 S. Karger AG, Basel

E-Mail karger@karger.com

www.karger.com/oop eye (OS) and was treated with plaque radiotherapy. He had a strong family history of cancer, and clinical testing for germline BAP1 mutation identified a pathogenic mutation in $B A P 1$. At the 18-month follow-up, visual acuity was $20 / 200$ OS without evidence of systemic metastasis. Patient 2 initially presented at age 54 years with extensive, diffuse iris melanoma OD, initially treated with plaque radiotherapy, but local recurrence after 3 years necessitated enucleation. Four years later, a 6.0-mm-thick ciliary body melanoma OS was found and successfully treated with plaque radiotherapy. Clinical testing for germline BAP1 mutation identified a pathogenic mutation in BAP1. At the 8-year follow-up, visual acuity was 20/40 OS without evidence of local recurrence or systemic metastasis. The patient expired secondary to an unrelated brain infarction. Conclusion: Bilateral uveal melano$\mathrm{ma}$ is exceedingly rare. Patients with bilateral uveal melanoma, especially when coincident with remote systemic 
cancers or a family history of cancer, should be evaluated for germline BAP1 mutation. Lifelong monitoring for related systemic malignancies is advised.

(c) 2019 S. Karger AG, Basel

\section{Introduction}

Uveal melanoma is principally a unifocal and unilateral intraocular tumor [1], with rare reports of multifocal melanoma arising in one eye [2] or both eyes [3-9]. The first bilateral uveal melanoma was published in 1959 by Wiesinger et al. [3], who described a 32-year-old woman with a family history of leukemia and bilateral uveal melanoma. The patient finally expired secondary to leukemia. Later, in 1977, the second recording of bilateral uveal melanoma was published by Shammas and Watzke [4], who described a 55-year-old woman with sequential development of bilateral primary choroidal melanoma over 4 years. Using the lifetime risk of unilateral uveal melanoma and assuming a purely stochastic incidence of melanoma, Shammas and Watzke extrapolated the incidence of bilateral melanoma, estimating it to occur once every 18 years in the USA, at a rate of 1 in every 50 million Caucasians [4].

A subsequent study from our department in 1996 revealed 8 cases of bilateral uveal melanoma in a cohort of 4,500 patients at Wills Eye Hospital [5]. At 0.18\%, this bilaterality rate was significantly higher than that reported by Shammas and Watzke [4]. Of the 8 cases, 2 (25\%) displayed bilateral oculodermal melanocytosis, an established predisposing condition for bilateral uveal melanoma. The remaining 6 (75\%) cases, however, showed no melanocytosis, suggesting the possibility of an underlying cancer predisposition syndrome [5].

Recently, sequencing of highly metastatic uveal melanomas has identified an associated inactivating mutation on the gene encoding BRCA1-associated protein 1 (BAP1) $[2,10-14]$. These findings implicate loss of $B A P 1$ in uveal melanoma and suggest that there might, indeed, be more factors responsible for the bilaterality of uveal melanoma than chance alone. Herein, we report 2 cases of multifocal and bilateral uveal melanoma in which laboratory evaluation ultimately revealed germline BAP1 mutation.

\section{Case 1}

A 48-year-old Caucasian man was referred for a ciliary body melanoma in the left eye (OS). Four years prior, his right eye (OD) was enucleated elsewhere for multifocal uveal melanoma. Histo- pathologic examination of the enucleated globe OD revealed 2 noncontiguous class $1 \mathrm{~A}$ mixed cell melanomas by gene expression profile testing. Clinical examination OS at the time was reportedly unremarkable. The patient was otherwise systemically healthy, with no history of cutaneous melanoma, immunosuppression, or presumed systemic malignancy. Family history was significant for ovarian and bladder cancer in his mother and pancreatic cancer in his maternal great grandfather.

On our examination, the anophthalmic right socket was healthy without evidence of tumor recurrence (Fig. 1a). Visual acuity OS was 20/40, with intraocular pressure of $13 \mathrm{~mm} \mathrm{Hg}$ and no evidence of ocular melanocytosis. Slit-lamp examination revealed a new left eye ciliary body lesion (Fig. 1b). Funduscopically, there was a pigmented iridociliochoroidal melanoma inferonasal to the optic disc measuring $16.0 \times 16.0 \mathrm{~mm}$ at base. B-scan ultrasonography showed a cavitary mushroom-shaped melanoma measuring $10.2 \mathrm{~mm}$ in thickness (Fig. 1c). Iodine-125 plaque radiotherapy was recommended. Cytogenetic profile of the tumor revealed disomy of chromosomes 3,6, and 8. Germline genetic testing in a clinical laboratory identified a pathogenic frameshift mutation in BAP1, c.1717delC.

On follow-up 18 months later, tumor regression to $4.0-\mathrm{mm}$ thickness was documented. There was no evidence of systemic metastasis.

\section{Case 2}

A 54-year-old Caucasian man was found to have an enlarging iris lesion OD with secondary glaucoma, refractory to topical medication. On referral, visual acuity was 20/30 OD and 20/20 OS, with intraocular pressure of $30 \mathrm{~mm} \mathrm{Hg} \mathrm{OD}$ and $14 \mathrm{~mm} \mathrm{Hg}$ OS. There was no evidence of ocular melanocytosis. Examination of the left eye was normal. Slit-lamp examination of OD revealed a flat pigmented iris melanoma measuring $4.0 \times 4.0 \times 2.5 \mathrm{~mm}$ in diameter between 3:00 and 6:00 and satellite lesions at 7.00, 8.00, 9.00, and 10.00 (Fig. 2a). Gonioscopy showed 360 degrees of dense pigmentation within the angle. Three years after treatment with Iodine- 125 plaque radiotherapy, local tumor recurrence led to enucleation. Histopathology confirmed epithelioid cell melanoma.

Four years after enucleation, the left eye was discovered to have a ciliary body melanoma of $10 \mathrm{~mm}$ in diameter (Fig. 2b) and 6.0 $\mathrm{mm}$ in thickness by ultrasonography (Fig. 2c). Cytogenetic profile revealed chromosome 3 monosomy, chromosome 6 disomy, and chromosome $8 \mathrm{q}$ amplification. Sequence analysis of the $B A P 1$ gene revealed a known pathogenic frameshift mutation, c.79delG, in exon 3. On follow-up 8 years later, tumor regression to $1.3-\mathrm{mm}$ thickness was documented. There was no evidence of systemic metastasis. The patient died the following year from a cerebrovascular infarction.

\section{Discussion}

When Shammas and Watzke [4] first extrapolated the incidence of bilateral melanoma in their populationbased study, the occurrence of bilateral primary uveal 

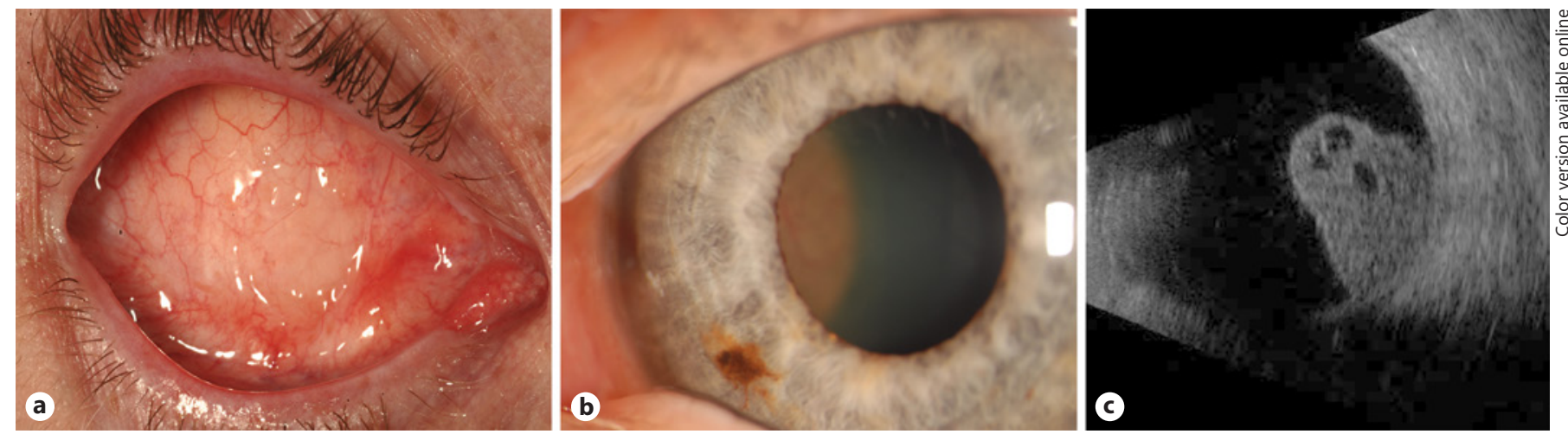

Fig. 1. Case 1: bilateral primary uveal melanoma in $B A P 1$ germline mutation. a The anophthalmic socket OD following enucleation (elsewhere) for multifocal melanoma. b Four years later, slit-lamp examination revealed a new ciliary body lesion in the left eye. c Ultrasonography OS revealed a cavitary mushroom-shaped ciliary body melanoma.
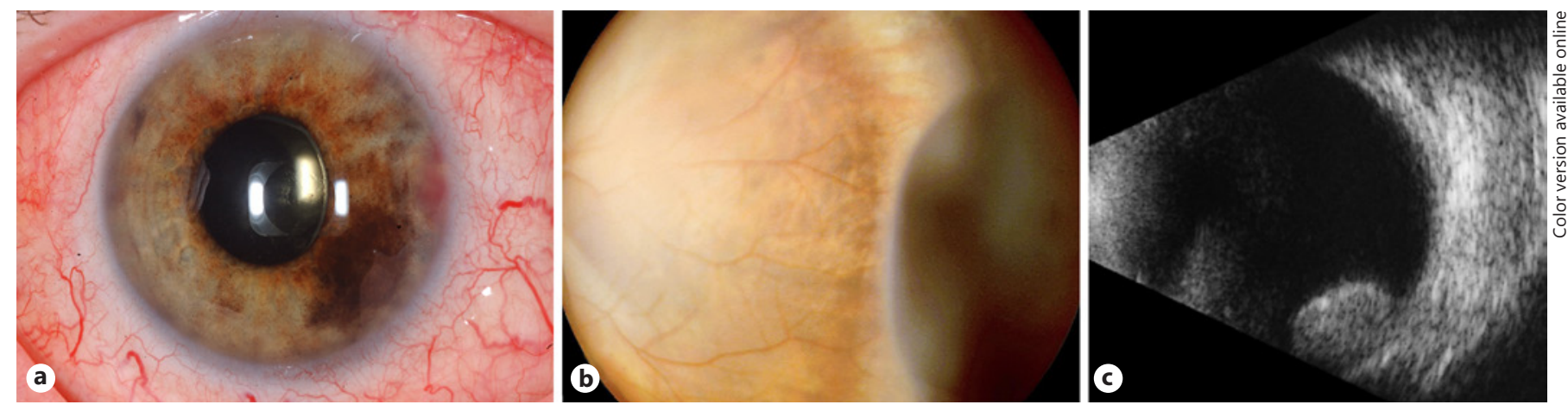

Fig. 2. Case 2: bilateral primary uveal melanoma in $B A P 1$ germline mutation. a Slit-lamp examination OD showed diffuse iris melanoma with heavy-angle pigmentary seeding and minor hyphema. This eye was treated with plaque radiotherapy and later enucle-

melanoma was thought to be a rare, random event, with odds deducible by statistics alone [3-9]. However, three subsequent independent reviews of patients with uveal melanoma have reported consistently higher rates of bilateral primary uveal melanoma, equating to $1.5-2$ per 1,000 cases $(0.15-0.20 \%)$ of unilateral primary uveal melanoma $[5,14,15]$. These clinic-based reviews might more accurately reflect the true incidence of bilateral primary uveal melanoma. Compared to a cross-sectional, population-based study, referral center-based reviews are better equipped to capture rare cases of bilaterality. The ability to examine follow-up data also increases the chance of identifying cases of sequential involvement of the contralateral eye, which are seen more often than those with simultaneous involvement of both eyes. In one systematic review of 52 cases of bilateral uveal mela- ation. b Seven years following enucleation, a new ciliary body lesion was discovered in the left eye. c Ultrasonography of the lesion OS showed a dome-shaped ciliary body mass. noma [6], most (69\%) of the bilateral cases presented initially as unilateral tumors, with sequential bilateral involvement occurring between 22 months [5] and 10 years [6] later.

The discrepancy between the observed and the expected incidence of bilateral melanoma might indicate the presence of predisposing factors to bilateral tumors. Environmental factors, such as arc welding and immunosuppression, have been proposed $[7,16]$. Bilateral oculo(dermal) melanocytosis has been identified as a possible risk factor for bilateral uveal melanoma [17, 18], with pre-existing ocular melanocytosis described in 12 $25 \%$ of bilateral uveal melanoma patients $[5,6]$.

The bilaterality of a primary cancer in a paired organ, however, has always been highly suggestive of an inherited cancer predisposition [19]. The most preva- 
lent examples include hereditary bilateral breast carcinoma in patients with germline BRCA1 and BRCA2 mutation $[19,20]$, bilateral renal cell carcinoma and retinal hemangioblastoma in von Hippel-Lindau (VHL) syndrome with germline VHL mutation [21], and bilateral retinoblastoma (RB) in patients with germline RB1 mutation [1]. Such observations, coupled with the discrepancy between the observed and expected frequencies of bilateral primary uveal melanoma, have led many to speculate a genetic predisposition $[5,6]$.

Although no genes have been implicated in the pathogenesis of bilateral uveal melanoma, $B A P 1$ has been identified as a high-penetrance gene for hereditary uveal melanoma (familial uveal melanoma) [11]. Mutation of this gene follows an autosomal dominant inheritance pattern and causes a spectrum of systemic malignancies (BAP1 tumor predisposition syndrome) $[11,12]$. An analysis of 174 cases of patients with germline BAP1 mutation showed preponderance for uveal melanoma (31\%), followed by malignant mesothelioma (22\%), atypical Spitz tumor (18\%), cutaneous melanoma (13\%), renal cell carcinoma (10\%), and others [12]. The risk for developing uveal melanoma in the presence of BAP1 germline mutation is estimated at up to $29 \%$ [12], and it is associated with class 2 uveal melanoma tumors and poor survival [11]. Subsequent publications have reported BAP1 germline mutation in patients with familial uveal melanoma [14], multifocal uveal melanoma in a single eye [2], and growth of nevus to melanoma in a predisposed patient [22].

Based on our experience and reports in the literature, we propose a simple "rule of twos" to serve as a guideline for considering BAP1 testing. We propose BAP1 testing should be performed in patients with (i) two or more BAP1-related cancers (particularly uveal melanoma, cutaneous melanoma, renal cell carcinoma, or malignant mesothelioma) in a single patient, (ii) two or more suspected primary sites of uveal melanoma in one eye (multifocal) [2] or both eyes (bilateral), or (iii) two or more family members (first or second-degree relatives) with $B A P 1$-related cancers [12]. An early age of onset of any $B A P 1$-associated tumors should also warrant consideration for $B A P 1$ testing [13].

Both patients in our series presented with ciliary body melanoma in the contralateral eye, a finding described by Gupta et al. [23] in a comparative study on 507 patients with uveal melanoma, in which $1.6 \%$ demonstrated a pathogenic germline BAP1 mutation. The study showed a preponderance for ciliary body involvement in patients with $B A P 1$ mutation compared to those without ( 75 vs. $22 \%, p=0.002$ ). Furthermore, risk for metastasis was significantly greater with $B A P 1$ germline mutation ( 71 vs. $18 \%, p=0.003$ ), although neither of our 2 patients has shown metastatic disease on early followup.

Theoretically, bilateral uveal melanoma could result from metastases of a primary tumor to the contralateral eye or from a nonocular primary site (e.g., cutaneous melanoma) to one or both eyes. In our series, however, a full systemic workup revealed neither extraocular metastasis nor nonocular melanoma in either patient. Thus, both cases likely represent true cases of primary bilateral disease. To the best of our knowledge, this is the first report of bilateral uveal melanoma in patients with germline $B A P 1$ mutation, following the prediction made in our publication from 1996 regarding a yet unidentified inherited genetic predisposition for bilateral uveal melanoma [5].

Of note, the mutation identified in patient 1 , c. $1717 \mathrm{delC}$, is a founder mutation originally described by Carbone et al. [24] and since reported by others as well $[13,25]$. In our patient, this mutation was uniquely associated with two uveal melanomas that were class 1 and disomy 3 , which is unusual in germline BAP1 pathogenic mutations. It is plausible that biallelic inactivation of BAP1 resulted from mutation or epigenetic inactivation.

In summary, we describe a rare entity of sequentially bilateral primary uveal melanoma in 2 patients with germline $B A P 1$ mutation. In patients with positive $B A P 1$ mutation, the possibility of bilateral disease should be considered when deciding enucleation versus conservative treatment. Close monitoring for related systemic cancers is advised.

\section{Acknowledgements}

Cytogenetic consultation was provided by Arupa Ganguly, $\mathrm{PhD}$, Genetic Diagnostic Laboratory, University of Pennsylvania (Philadelphia, PA, USA).

\section{Statement of Ethics}

The study protocol was exempted by the Wills Eye Hospital Institutional Review Board. The study was conducted in accordance with the tenets of the Declaration of Helsinki or comparable ethical standards. Patient consent was obtained for the publication of medical history and imaging. 


\section{Disclosure Statement}

Support was provided by the Eye Tumor Research Foundation, Philadelphia, PA (to C.L.S.). The funders had no role in the design and conduct of the study, in the collection, analysis and interpreta- tion of the data, and in the preparation, review or approval of the paper. Carol L. Shields, MD, had full access to all the data in the study and takes responsibility for the integrity of the data and the accuracy of the data analysis. No conflicting relationship exists for any author.

\section{References}

1 Shields JA, Shields CL. Intraocular tumors: An Atlas and Text. 3rd ed. Philadelphia (PA): Lippincott Wolters Kluwer; 2016. p. 45-59.

2 Rao R, Pointdujour-Lim R, Ganguly A, Shields CL. Multifocal choroidal melanoma in a patient with germline BRCA1-associated protein 1 mutation. Retin Cases Brief Rep. 2018;12(1):1-4.

3 Wiesinger H, Phipps GW, Guerry D 3rd. Bilateral melanoma of the choroid associated with leukemia and meningioma. Arch Ophthalmol. 1959 Nov;62(5):889-93.

4 Shammas HF, Watzke RC. Bilateral choroidal melanomas. Case report and incidence. Arch Ophthalmol. 1977 Apr;95(4):617-23.

5 Singh AD, Shields CL, Shields JA, De Potter P. Bilateral primary uveal melanoma. Bad luck or bad genes? Ophthalmology. $1996 \mathrm{Feb}$; 103(2):256-62.

6 Scott JF, Vyas R, Galvin J, Gotow E. Primary bilateral uveal melanoma: a population-based study and systematic review. Clin Exp Ophthalmol. 2018 Jul;46(5):502-10.

7 Turaka K, Shields CL, Shah CP, Say EA, Shields JA. Bilateral uveal melanoma in an arc welder. Graefes Arch Clin Exp Ophthalmol. 2011 Jan;249(1):141-4.

8 Eide N, Garred $\varnothing$, Beiske K, Fodstad Ø. Bilateral uveal melanomas with different gene expression detected with 7 years interval. Acta Ophthalmol. 2016 Feb;94(1):99-102.

9 Furuta M, Shields CL, Uysal Y, Shields JA. Bilateral primary choroidal melanoma treated with bilateral plaque radiotherapy: a report of three cases. Eur J Ophthalmol. 2006 Nov-Dec; 16(6):879-82

10 Harbour JW, Onken MD, Roberson ED, Duan S, Cao L, Worley LA, et al. Frequent mu- tation of BAP1 in metastasizing uveal melanomas. Science. 2010 Dec;330(6009):1410-3.

11 Abdel-Rahman MH, Pilarski R, Cebulla CM, Massengill JB, Christopher BN, Boru G, et al. Germline BAP1 mutation predisposes to uveal melanoma, lung adenocarcinoma, meningioma, and other cancers. J Med Genet. 2011 Dec;48(12):856-9.

12 Rai K, Pilarski R, Cebulla CM, Abdel-Rahman $\mathrm{MH}$. Comprehensive review of BAP1 tumor predisposition syndrome with report of two new cases. Clin Genet. 2016 Mar;89(3):28594.

13 Cebulla CM, Binkley EM, Pilarski R, Massengill JB, Rai K, Liebner DA, et al. Analysis of BAP1 germline gene mutation in young uveal melanoma patients. Ophthalmic Genet. 2015 Jun;36(2):126-31.

14 Bhouri L, Lumbroso L, Levy C, Dendale R, Asselain B, Plancher C, et al. [Bilateral uveal melanomas. Five case reports]. J Fr Ophtalmol. 2003 Feb;26(2):149-53.

15 Shields CL, Kaliki S, Furuta M, Mashayekhi A, Shields JA. Clinical spectrum and prognosis of uveal melanoma based on age at presentation in 8,033 cases. Retina. 2012 Jul;32(7): 1363-72.

16 Buda G, Romagnoli MC, Galimberti S, Figus M, Papineschi F, Nardi M, et al. Simultaneous appearance of acute myeloid leukemia in a patient with bilateral primary uveal melanoma. Melanoma Res. 2006 Oct;16(5):467-8.

17 Gonder JR, Shields JA, Shakin JL, Albert DM. Bilateral ocular melanocytosis with malignant melanoma of the choroid. Br J Ophthalmol. 1981 Dec;65(12):843-5.

18 Honavar SG, Shields CL, Singh AD, Demirci $\mathrm{H}$, Rutledge BK, Shields JA, et al. Two discrete choroidal melanomas in an eye with ocular melanocytosis. Surv Ophthalmol. 2002 JanFeb;47(1):36-41.

19 Den Otter W, Koten JW, Van der Vegt BJ, Beemer FA, Boxma OJ, De Graaf PW, et al. Hereditary cancer and its clinical implications: a view. Anticancer Res. 1990 Mar-Apr; 10 2B:489-95.

20 Valencia OM, Samuel SE, Viscusi RK, Riall TS, Neumayer LA, Aziz H. The role of genetic testing in patients with breast cancer: a review. JAMA Surg. 2017 Jun;152(6):589-94.

21 Agaimy A, Hartmann A. [Hereditary renal tumors: more common than expected?]. Pathologe. 2016 Mar;37(2):134-43. German.

22 Masoomian B, Shields JA, Mashayekhi A, Ganguly A, Shields CL. Growth of presumed choroidal nevus into melanoma over 4 years in BAP1 tumor predisposition syndrome. Retin Cases Brief Rep. 2018. DOI: 10.1097/ ICB.0000000000000772. Epub ahead of print.

23 Gupta MP, Lane AM, DeAngelis MM, Mayne K, Crabtree M, Gragoudas ES, et al. Clinical characteristics of uveal melanoma in patients with germline BAP1 mutations. JAMA Ophthalmol. 2015 Aug;133(8):881-7.

24 Carbone M, Flores EG, Emi M, Johnson TA, Tsunoda T, Behner D, et al. Combined genetic and genealogic studies uncover a large BAP1 cancer syndrome kindred tracing back nine generations to a common ancestor from the 1700s. PLoS Genet. 2015 Dec;11(12): e1005633.

25 Rai K, Pilarski R, Boru G, Rehman M, Saqr $\mathrm{AH}$, Massengill JB, et al. Germline BAP1 alterations in familial uveal melanoma. Genes Chromosomes Cancer. 2017 Feb;56(2):16874. 